BMJ Open Sport \& Exercise Medicine

\title{
More people more active, but there is a counter site. Novice athletes are at highest risk of injury in a large population-based retrospective cross- sectional study
}

\author{
Ellen Kemler (D) , ${ }^{1}$ Huib Valkenberg, ${ }^{1}$ Evert Verhagen (D) ${ }^{2}$
}

To cite: Kemler E, Valkenberg $\mathrm{H}$, Verhagen $\mathrm{E}$. More people more active, but there is a counter site. Novice athletes are at highest risk of injury in a large population-based retrospective cross-sectional study. BMJ Open Sport \& Exercise Medicine 2022;8:e001255. doi:10.1136/ bmjsem-2021-001255

Accepted 29 December 2021
Check for updates

(c) Author(s) (or their employer(s)) 2022. Re-use permitted under CC BY-NC. No commercial re-use. See rights and permissions. Published by BMJ.

${ }^{1}$ Dutch Consumer Safety Institute, Amsterdam, the Netherlands

${ }^{2}$ Amsterdam Collaboration on Health \& Safety in Sports, Department of Public and Occupational Health, Amsterdam Movement Sciences, Amsterdam UMC, University Medical Centers - Vrije Universiteit Amsterdam, Amsterdam, the Netherlands

Correspondence to Dr Ellen Kemler; e.kemler@veiligheid.nl

\section{ABSTRACT}

Objectives To evaluate whether in fitness-related activities and recreational running over time, there is an increase in the number of novice sports athletes and whether these novice athletes have an increased injury rate compared with their experienced counterparts. Methods Data were collected from a large populationbased retrospective cross-sectional study, 'Injuries and Physical Activity in the Netherlands' (IPAN). Athletes aged $\geq 18$ years were included. We used descriptive statistics to describe the characteristics of athletes and their injuries. The number of athletes and injuries were calculated for each year and, where applicable, for each sport separately. The injury incidence rate was expressed as the number of injuries per 1000 hours of exposure. Logistic regression analyses were performed with nonextrapolated data to analyse the differences in injury risk for novice and experienced athletes included in this study, separate for fitness-related activities and running.

Results Over the 5 years, 9209 fitness athletes reported 370 fitness-related injuries, 5426 runners reported 537 running-related injuries. Weighted data showed that, in 2010-2014, the inflow of novice fitness athletes slightly decreased, whereas the inflow of novice runners slightly increased. In each year, injury risk was higher in novice athletes compared with experienced athletes for both fitness-related activities and running. The injury incidence rates in running are much higher than in fitness-related activities.

Conclusions Over the years 2010-2014, the absolute number of novice athletes in fitness-related activities and running together increased. Although most injuries occurred in experienced athletes, injury risk was higher in novice athletes in both sports.

\section{INTRODUCTION}

The impact of (in)sufficient levels of physical activity has been well described and, without argument, the promotion of physical activity is now a cornerstone of contemporary public health. ${ }^{12}$ Although evidence suggests that participation in sport, recreation and physical activity are beneficial from a health

\section{Key messages}

What is already known

- The promotion of physical activity is a cornerstone of contemporary public health.

- Novice participants have a distinctly higher risk of injury than more experienced participants.

- With the contemporary focus on physical activity promotion, more physical activity and sports participants can be expected, and, thus, the number of novice participants with a higher risk of injury is expected to increase.

\section{What are the new findings}

- Over the years 2010-2014, the inflow of novice fitness athletes in absolute numbers slightly decreased, the inflow of novice recreational runners increased.

- Although, in absolute numbers, most injuries oc curred in experienced athletes, injury risk was highest in novice athletes in both fitness-related activities and running.

perspective, injuries incurred during these activities have significant short and longterm negative side effects. These injuries are an important contributor to total disease morbidity. Within the EU, for instance, it was estimated that as a result of participation in sport, 5.8 million acute injuries are sustained and treated at emergency departments (EDs) annually across all age groups and levels, and 24.6 million acute injuries for home, leisure (including physical activity) and sport activities in total. ${ }^{3-5}$ Next to a burden to the injured individual, these injuries pose a substantial societal burden as well. This societal impact is clearly illustrated by the approximated shortterm costs alone, which sum up to 50 billion $€$ per year for home, leisure and sport injuries treated at EDs. ${ }^{4}$ The actual costs of injury are likely to be much higher, due to, for example, sick pay, cost for treatments outside 
of hospital, costs for rehabilitation, disability pensions and loss of productivity.

The short-term and long-term benefits of sufficient physical activity and participation in sport outweigh by far the potential negative consequence. Yet, this does not mean that we can ignore the existence of such side effects. ${ }^{6}$ Especially given reports suggesting that novice and recreational participants have a distinctly higher risk of injury than more experienced participants. A review on injury rates in long distance runners, for instance, established that novice runners have a higher injury rate (2.56 injuries/1000 hours; $95 \%$ CI 2.55 to 2.60) than recreational runners (2.06 injuries/1000 hours; $95 \%$ CI 1.70 to 1.90 ), who, in turn, have a higher injury rate than competitive runners (1.55 injuries/1000 hours; 95\% CI 1.54 to 1.56$).{ }^{7}$ Similar differences have been found for children $^{8}$ and soccer. ${ }^{9}$

With the contemporary focus on physical activity promotion, ${ }^{12}$ more physical activity and sport participants can be expected, and, thus, the number of novice participants will logically increase. In the Netherlands, for instance, adults participate mostly in fitness-related activities and recreational running, and between 2001 and 2018, both sports have seen an increase in participation rates of, respectively, $10,8 \%$ and $6,7 \% .{ }^{10}$ In line with such a development, the number of injuries in these sports is hypothesised to accrue at an increased rate. The current analysis evaluated for fitness-related activities and recreational running-based on population participation and injury data-whether there is an increase over time in the number of novice athletes and whether these have an increased injury rate compared with their experienced counterparts.

\section{METHODS}

To provide insight into the number of novice athletes and their injury risk compared with their experienced counterparts, data were collected from a large populationbased retrospective cross-sectional study, 'Injuries and Physical Activity in the Netherlands' (IPAN). IPAN is an existing database, data were registered anonymously, and respondents cannot be traced with this data.

\section{Patient and public involvement}

Given the research design, it was not appropriate or possible to involve patients or the public in the design, or conduct, or reporting or dissemination plans of our research.

\section{Injuries and physical activity in the Netherlands}

IPAN was a continuous national questionnaire on accidents, injuries, sport participation and physical activity, operated by the Dutch Consumer Safety Institute (VeiligheidNL) from 2010 till 2014. IPAN consisted of a general section in which information on demographic characteristics, general health and activity, occupation, education was gathered, and four accident or injuryspecific sections: traffic accidents, home and leisure accidents, sport injuries and occupational accidents.

All respondents of IPAN were participants of InterviewBase, a database of around 238000 people in the
Netherlands willing to contribute to research. New respondents for this database were continuously recruited on the internet or by random digit dialling. Each year, a representative sample of around 11000 members was questioned for IPAN, either by telephone or online. To optimise the representativeness, sociodemographic quotas for this sample were established in advance. During the 5 years used for this study (2010-2014), 43508 respondents aged 18 and older were questioned for IPAN. To correct for differences in non-response within the quota groups, the data were standardised to the Dutch population by weighing the questionnaire data for age, gender, level of education, employment, urbanity, living region and household size based on data from the Dutch Central Bureau of Statistics, using random iterative method weighting. ${ }^{11}$

\section{Data selection procedure}

For the present study, data were used from the general and sport injury sections of IPAN. Athletes aged $\geq 18$ years were included in this study. In IPAN, a maximum of four sports were registered per athlete. This study included fitness-related activities and running because Dutch adults participate mostly in fitness-related activities and recreational running. Both sports have seen increased participation rates between 2001 and 2018. ${ }^{10}$ Fitness is an umbrella term for all sports usually practised in a gym. The activities can be divided in cardio fitness, such as home trainer, treadmill, rowing machine; weight training/body building: weightlifting fitness equipment, weight lifting/ squats, use of dumbbells; group fitness: CrossFit, aerobics, Pilates, Zumba, spinning, Steps, bootcamp, body balance, body shape, body pump, callisthenics.

Information on sports experience (novice or experienced) and hours of sport participation were gathered per sports type. Athletes who started a sport during the past 12 months were defined as 'novice' in this sport. Those who participated in a sport for more than 12 months were defined as 'experienced'. Hence, an athlete could be both novice in one sport and experienced in another sport.

Per sport, exposure per athlete was calculated. The reported average weekly exposure (sessions per week * time per session in hours) was multiplied by the number of weeks per year an athlete reported being active in that sport. The total amount of sport participation per athlete was the sum of the total hours of sport participation per sport.

In IPAN's sport section, information on sport injuries was gathered. The recall period for reporting injuries was set at 3 months. With the first day of the recall period, always set at the beginning of a month-and respondents were interviewed on all days of the month-individual respondents recall period could range from 3 to 4 months. Therefore, the length of the recall period was set on an average of 3.5 months. ${ }^{12}$ To calculate the annual number of new injuries per sport, the registered selfreported number of injuries within the recall period was 
multiplied by $12 / 3.5$. Athletes could report a maximum number of two new sport injuries within the recall period. Before an injury was included in the analyses, one of the authors (EK) checked that it agreed with the (general) sport injury definition by Schmikli et al: 'Physical damage of a musculoskeletal nature as a result of a sudden event during a sports activity or as a result of a gradual process related to sports activity'. ${ }^{12}$ A minimum of 50 new injuries per sport per year was chosen for the reliability of the analyses. This assumption was met for both fitness-related activities and running.

While athletes could be active in more than one sport, information on sports experience (novice or experienced) was established per sport separately. Hence, we display information of novice and experienced athletes for fitness-related activities and running separately.

\section{Statistical analysis}

We used descriptive statistics to describe the characteristics of athletes and their injuries. We calculated the number of athletes and the number of injuries each year and, when applicable, for each sport separately. The injury incidence rate was expressed as the number of injuries per 1000 hours of exposure. The injury incidence rate and $95 \% \mathrm{CI}$ were calculated manually in Microsoft 365 Excel. Logistic regression analyses were performed with non-extrapolated data to compare the odds for injury between novice and experienced athletes, separate for fitness-related activities and running. The year of response (2010-2014) and exposure (hours of fitness-related activities or running) were included in the model as covariates. Analyses were controlled for effect modification by adding interaction terms. We performed all analyses using the Statistical Package for the Social Sciences (IBM SPSS, V.23.0), with a significance level of $\mathrm{p}<0.05$.

\section{RESULTS}

In our study over 5 years, 28773 athletes aged 18 years and older reported a total of 2903 sport injuries. Of the 28773 athletes in 2010-2014, 9209 were active in fitnessrelated activities (37\% male, mean ages 41.9 years; SD $15.3)$, and 5426 were runners (52\% male, mean age 35.5 years; SD 11.8). In total, over the 5 years, the fitness athletes reported 370 fitness-related injuries, the runners reported 537 running-related injuries. The reported injuries per sport per year ranged from 55 (fitness, 2011) to 132 (running, 2014).

\section{Sports participation and injuries in the Netherlands}

Weighted data showed that, in 2010, 8.77 million individuals in the Netherlands aged 18 and older participated in sports. This corresponded to approximately 53\% of the total Dutch population. Between 2010 and 2014, this number increased to 9.17 million. The total number of sport injuries and the injury incidence rate gradually increased over time (table 1 ).

\section{Fitness-related activities}

Over our 5-year period, the number of fitness athletes increased from 2.64 million to 2.94 million (table 2). In 2010, almost one-third of the fitness athletes were considered a novice. In 2014, the percentage of novice fitness athletes in the fitness population had decreased to $25 \%$. Over the years, the number of injuries in fitnessrelated activities gradually increased from 304000 in 2010 to 487000 in 2014, and most injuries occurred in experienced fitness athletes. The incidence rate of fitness injuries significantly increased from 1.3 (95\% CI 1.24 to 1.38) injuries per 1000 hours of participation in 2010 to 1.8 (95\% CI 1.72 to 1.88 ) injuries per 1000 hours of participation in 2014. Each year, the injury incidence rate in novice fitness athletes was higher than in experienced fitness athletes (figure 1 and table 2).

A logistic regression analysis was performed on nonextrapolated data to analyse the odds for injury for all novice and experienced fitness athletes, taking the year of response (2010-2014) and exposure (hours of fitness) into account. No effect modification was found. The OR for sustaining a fitness-related injury did not differ between novice and experienced fitness participants (OR 0.91 ; 95 CI 0.74 to 1.13 ; table 3 ).

\section{Running}

Over the 5 years, the number of runners increased by more than half a million (table 4). There was an increase in both experienced and novice runners. With increasing numbers of runners, the number of injuries increased as well. The number of injuries for all runners doubled over 5 years from 336000 to 688000 , and most injuries occurred in experienced runners. Like experienced fitness athletes, experienced runners are, on average, also more active in running than their novice counterparts. Each year, the injury incidence rate in novice runners is significantly higher when compared with experienced runners (see also figure 2).

Table 1 Athletes and injuries in the Netherlands over the period 2010-2014

\begin{tabular}{llllll}
\hline & $\mathbf{2 0 1 0}$ & $\mathbf{2 0 1 1}$ & $\mathbf{2 0 1 2}$ & $\mathbf{2 0 1 3}$ & $\mathbf{2 0 1 4}$ \\
\hline Athletes & 8770000 & 8740000 & 8990000 & 9370000 & 9170000 \\
Injuries & 2820000 & 2970000 & 3300000 & 3470000 & 3590000 \\
Injured athletes (\%) & 11.6 & 12.5 & 13.0 & 13.0 & 14.0 \\
Injuries/1000 hour sports & 1.8 & 1.8 & 2.0 & 2.0 & 2.1 \\
\hline
\end{tabular}


Table 2 Fitness athletes and injuries in the Netherlands over the period 2010-2014

\begin{tabular}{|c|c|c|c|c|c|}
\hline & 2010 & 2011 & 2012 & 2013 & 2014 \\
\hline Total fitness athletes & 2640000 & 2630000 & 2920000 & 2950000 & 2940000 \\
\hline Experienced fitness athletes, $\mathrm{n}(\%)$ & $\begin{array}{l}1770000 \\
(67.4 \%)\end{array}$ & $\begin{array}{l}1820000 \\
(69.3 \%)\end{array}$ & $\begin{array}{l}2060000 \\
(70.8 \%)\end{array}$ & $\begin{array}{l}2140000 \\
(72.5 \%)\end{array}$ & $\begin{array}{l}2210000 \\
(75.2 \%)\end{array}$ \\
\hline Novice fitness athletes, n (\%) & $\begin{array}{l}862000 \\
(32.7 \%)\end{array}$ & $\begin{array}{l}808000 \\
(30.7 \%)\end{array}$ & $\begin{array}{l}851000 \\
(29.2 \%)\end{array}$ & $\begin{array}{l}812000 \\
(27.5 \%)\end{array}$ & $\begin{array}{l}728000 \\
(24.8 \%)\end{array}$ \\
\hline Injuries total & 304000 & 298000 & 400000 & 421000 & 487000 \\
\hline Injuries experienced, $\mathrm{n}(\%)$ & $\begin{array}{l}181000 \\
(59.5 \%)\end{array}$ & $\begin{array}{l}242000 \\
(81.0 \%)\end{array}$ & $\begin{array}{l}288000 \\
(72.1 \%)\end{array}$ & $\begin{array}{l}310000 \\
(73.7 \%)\end{array}$ & $\begin{array}{l}359000 \\
(73.7 \%)\end{array}$ \\
\hline Injuries novice, n (\%) & $\begin{array}{l}123000 \\
(40.5 \%)\end{array}$ & $\begin{array}{l}56600 \\
(19.0 \%)\end{array}$ & $\begin{array}{l}112000 \\
(27.9 \%)\end{array}$ & $\begin{array}{l}111000 \\
(26.3 \%)\end{array}$ & $\begin{array}{l}128000 \\
(26.3 \%)\end{array}$ \\
\hline Mean $\mathrm{h} / \mathrm{y}$ total & 88.2 & 97.5 & 96.3 & 98.5 & 92.1 \\
\hline Mean $\mathrm{h} / \mathrm{y}$ experienced fitness athletes & 95.9 & 114.4 & 107.1 & 107.3 & 101.3 \\
\hline Mean $\mathrm{h} / \mathrm{y}$ novice fitness athletes & 72.1 & 58.5 & 69.5 & 74.8 & 63.4 \\
\hline $\begin{array}{l}\text { Injuries/1000 hours fitness total } \\
(95 \% \mathrm{Cl})\end{array}$ & $\begin{array}{l}1.3 \\
(1.24 \text { to } 1.38)\end{array}$ & $\begin{array}{l}1.2 \\
(1.10 \text { to } 1.23)\end{array}$ & $\begin{array}{l}1.4 \\
(1.35 \text { to } 1.50)\end{array}$ & $\begin{array}{l}1.4 \\
(1.37 \text { to } 1.52)\end{array}$ & $\begin{array}{l}1.8 \\
(1.72 \text { to } 1.88)\end{array}$ \\
\hline $\begin{array}{l}\text { Injuries/1000 hours fitness experienced } \\
(95 \% \mathrm{Cl})\end{array}$ & $\begin{array}{l}1.1^{*} \\
(1.00 \text { to } 1.13)\end{array}$ & $\begin{array}{l}1.2 \\
(1.09 \text { to } 1.23)\end{array}$ & $\begin{array}{l}1.3^{*} \\
(1.23 \text { to } 1.38)\end{array}$ & $\begin{array}{l}1.4^{*} \\
(1.28 \text { to } 1.42)\end{array}$ & $\begin{array}{l}1.6^{\star} \\
(1.53 \text { to } 1.68)\end{array}$ \\
\hline $\begin{array}{l}\text { Injuries/1000 hours fitness novice } \\
(95 \% \mathrm{Cl})\end{array}$ & $\begin{array}{l}2.0^{*} \\
(1.90 \text { to } 2.07)\end{array}$ & $\begin{array}{l}1.2 \\
(1.13 \text { to } 1.27)\end{array}$ & $\begin{array}{l}1.9^{*} \\
(1.81 \text { to } 1.98)\end{array}$ & $\begin{array}{l}1.8^{*} \\
(1.74 \text { to } 1.91)\end{array}$ & $\begin{array}{l}2.8^{*} \\
(2.67 \text { to } 2.87)\end{array}$ \\
\hline
\end{tabular}

*Significant difference between novice and experienced athletes.

A logistic regression analysis was performed on nonextrapolated data to analyse the odds for injury for all novice and experienced runners over the 5-year study period. Similar to fitness-related activities, response year and hours of running were included in the model as covariates. No effect modification was found. The Odds for sustaining a running injury was higher for novice runners than for experienced runners (OR 1.19; $95 \mathrm{CI}$ 1.00 to 1.42 ; table 5 ). Both response year and exposure were associated with the occurrence of a running-related injury as well.

\section{DISCUSSION}

In this study, we analysed whether, over time, there was an increase in the number of novice athletes in fitnessrelated activities and recreational running and whether novice athletes had a higher injury rate compared with

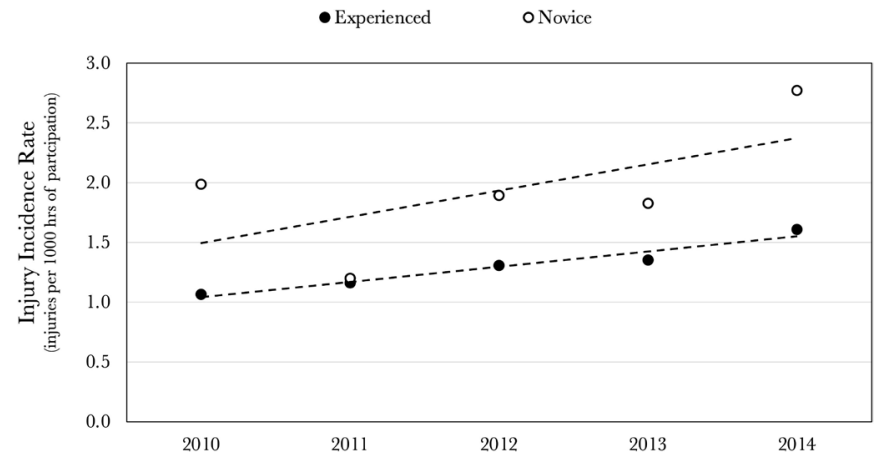

Figure 1 Incidence rates fitness-related injuries in 20102014 in the Netherlands. their experienced counterparts. Between 2010 and 2014, weighted data showed that the inflow of novice fitness athletes slightly decreased, while the inflow of novice runners slightly increased. Although in, both sports most injuries occurred in experienced athletes, the injury risk was higher in novice athletes.

Considering the vision of Exercise is Medicine, a global health initiative managed by the American College of Sports Medicine and the WHO, physical activity has significant health benefits for the heart, body and mind. Hence, the ongoing promotion of physical activity will be a cornerstone of public health. ${ }^{1}$ The promotion of sustainable sports is warranted. In our study, we observed a rather steady inflow of novice athletes. It is plausible that these novice athletes remained active, as there was

Table 3 Logistic regression analyses for sustaining a fitness-related injury

\begin{tabular}{lll}
\hline & OR $(95 \%$ Cl) & P-value \\
\hline $\begin{array}{l}\text { Experience (novice vs } \\
\text { experienced) }\end{array}$ & $0.91(0.74$ to 1.13$)$ & 0.416 \\
$\begin{array}{l}\text { Response year } \\
2010\end{array}$ & Reference category & 0.384 \\
2011 & $1.08(0.78$ to 1.49$)$ & 0.636 \\
2012 & $1.14(0.83$ to 1.55$)$ & 0.416 \\
2013 & $1.16(0.85$ to 1.58$)$ & 0.342 \\
2014 & $1.34(.099$ to 1.81$)$ & 0.056 \\
\hline Hours of exposure & $1.00(1.00$ to 1.00$)$ & 0.000 \\
\hline
\end{tabular}




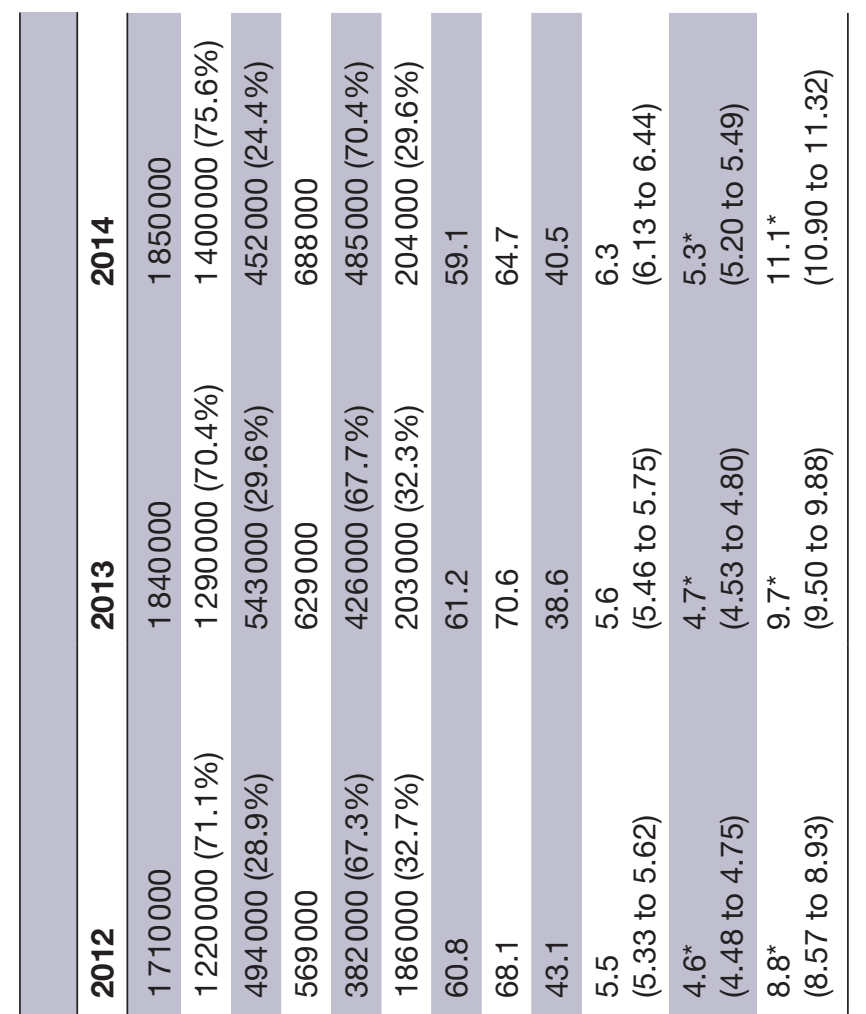

\section{a}

D

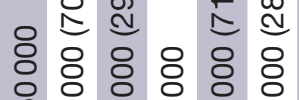

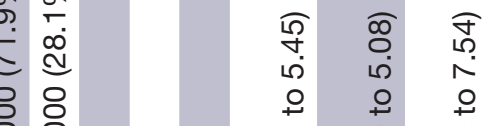

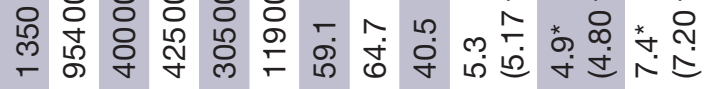

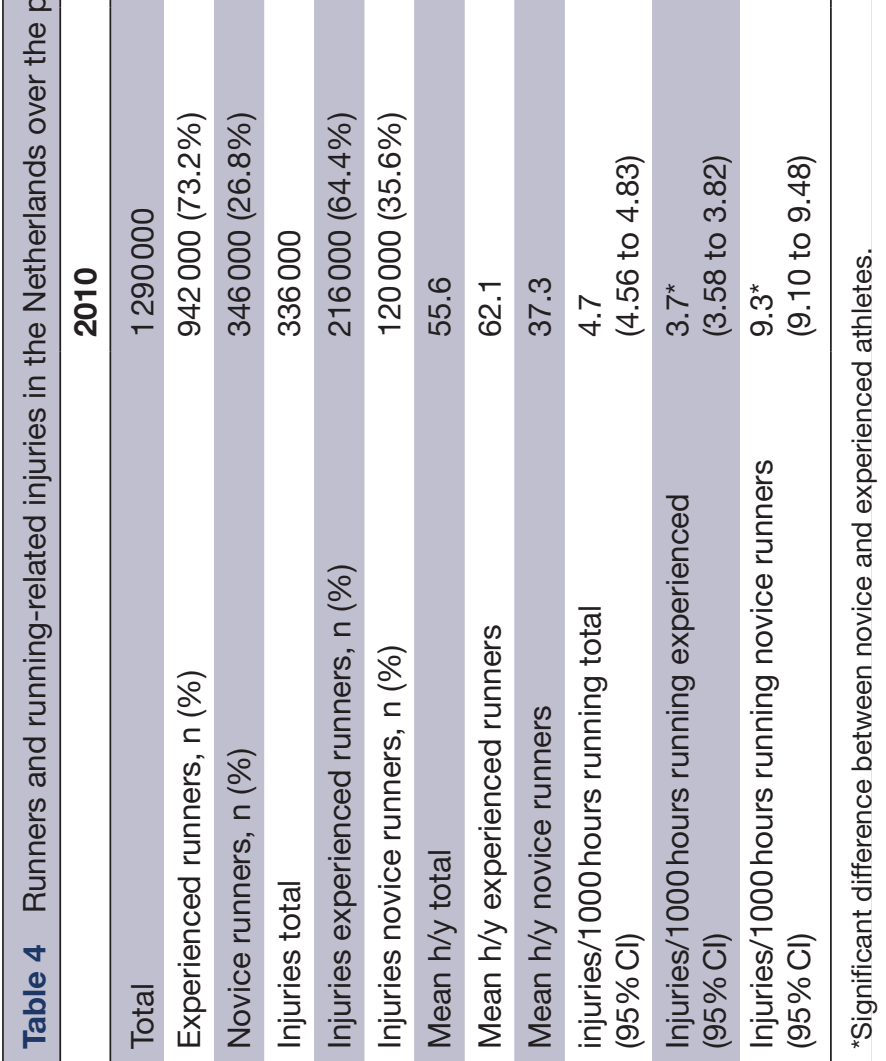




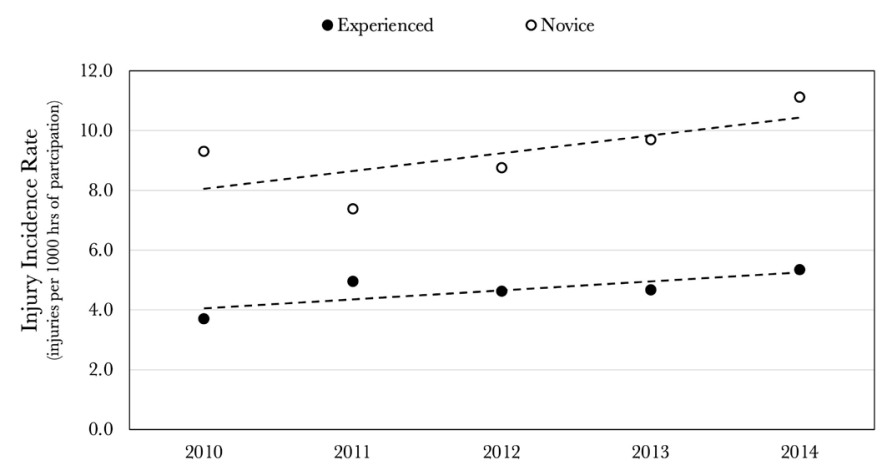

Figure 2 Incidence rates running-related injuries in 20202014 in the Netherlands.

a steady increase in fitness athletes and recreational runners over the years. These increasing numbers can be a representation of the successful promotion of physical activity in the Netherlands.

The possibility to sustain an injury is associated with being active in sports and physical activity. With increasing numbers of athletes, the number of injuries increased in both sports. Novice athletes did have a higher risk for injury than their experienced counterparts. An injury is one of the main reasons to quit physical activity. ${ }^{13}{ }^{14}$ With all the extra attention for becoming physically active and starting to participate in sports, especially in populations that are less physically fit, the number of injuries will likely increase with increasing numbers of novice athletes, limiting the additional value of physical activity for these athletes. Hence, we believe that attention to prevention is necessary to prevent early drop-out of sports of novice athletes. ${ }^{6}$

Not only is the injury risk of novice athletes higher but the duration of injury in novice athletes also is relatively long, specifically in novice runners, ${ }^{15}$ and a tendency towards receiving medical attention more frequently was found as well. ${ }^{16}$ Sport injuries are rarely the result of a single factor, ${ }^{17}$ nor will the differences in injury risk between novice and experienced athletes be. A consequence of this higher injury risk, long absence and healthcare consumption, and difference in risk factors, is that universal injury prevention is insufficient. Injury

Table 5 Logistic regression analyses for sustaining a running-related injury

\begin{tabular}{lll}
\hline & OR $(\mathbf{9 5 \%}$ Cl) & P-value \\
\hline $\begin{array}{l}\text { Experience (novice vs } \\
\text { experienced) }\end{array}$ & $1.19(1.00$ to 1.42$)$ & 0.045 \\
$\begin{array}{l}\text { Response year } \\
2010\end{array}$ & Reference category & 0.012 \\
\hline 2011 & $1.06(0.79$ to 1.42$)$ & 0.695 \\
2012 & $1.28(0.98$ to 1.68$)$ & 0.073 \\
2013 & $1.28(0.98$ to 1.70$)$ & 0.071 \\
2014 & $1.51(1.16$ to 1.97$)$ & 0.002 \\
\hline Hours of exposure & $1.00(1.00$ to 1.00$)$ & 0.000 \\
\hline
\end{tabular}

prevention should be context specific and focusing on a target group, in this case, the novice athletes. Research has demonstrated that many sport injuries can be prevented in ideal or pragmatic conditions. ${ }^{19}$ For example, for organised team sports in the Netherlands like, for example, soccer (FIFA 11+), volleyball ${ }^{20}$ and field hockey, ${ }^{21}$ effective injury prevention programmes exist. So far, not much evidence for injury prevention in novice athletes in running or fitness-related activities is available, neither in ideal nor in pragmatic conditions.

Although injury prevention is complicated, one aspect of novice athletes makes it even more difficult. An important aspect of being a novice athlete is the aspect of being unconscious incompetent, referring to the first stage of the 'four stages of competence'. ${ }^{22}$ Novice athletes, or most of them, do not understand or know how to prevent injuries and do not necessarily recognise the importance of prevention. If you do not have any experience with having a sport injury, you might not feel the urge to protect yourself against injury. Injury prevention is not a conscious decision for recreational runners but a tentative to control and influence the injury through a self-regulation process. ${ }^{23}$ Hence, we believe that effective interventions for experienced athletes should not simply be applied to beginners. As novice athletes differ from their experienced counterparts, and (implementation of) prevention is precarious, more research is needed to gain insight into novice athletes' 'complex world', their beliefs, motivation, knowledge, etcetera. Only then prevention for novice athletes might work.

\section{Limitations}

Some limitations of this study need to be addressed. First, all information in IPAN are based on self-report. Although this method may not yield the highest quality data because of potential patient bias ${ }^{24}$ and socially desirable responses, collecting information in large cohorts on all injuries, including less severe ones, is highly practical. Second, we classified athletes who had been active for less than a year as novice and athletes who had been active for more than a year as experienced. The choice for a 1-year boundary to distinguish between novice and experienced athletes is debatable. Athletes with more than 12 months of experience still could be very 'novice'. Athletes with 13 months of being active in sports once a week might be less experienced than those with 11 months of physical activity once a week. This is not considered in this study. Injury data in this study are not further specified for, for example, type of injury, injury location and different types of runners are grouped based on experience only. Although we believe that such specifications can be of interest, in this study, we chose otherwise because they are not directly related to the common thread of this study. Finally, there is a risk of recall bias. We asked athletes to answer questions concerning the last 3 months. This recall bias and the accuracy of self-reporting of sport injuries depend largely on the length of the recall period. ${ }^{2526}$ 
A recall period of 1-3 months is recommended for injury questionnaires, ${ }^{27}$ similar to that used in our study.

\section{CONCLUSION}

Over the years 2010-2014, the inflow of novice athletes ranged from $24.4 \%$ to $32.7 \%$; the inflow of novice fitness athletes slightly decreased, whereas the inflow of novice runners slightly increased. The absolute number of novice athletes in fitness-related activities and running together increased. Although most injuries occurred in experienced athletes, injury risk was higher in novice athletes in both sports. As lasting physical activity is beneficial for one's health, we believe that attention to prevention is necessary for novice athletes to prevent early dropout of sports. Furthermore, injury prevention should be context specific and focusing on the target group of interest.

\section{Twitter Ellen Kemler @ellenkemler and Evert Verhagen @evertverhagen}

Contributors EK was responsible for the conceptualisation of the idea of the study, data analyses, interpretation of the data and preparation of the manuscript. HV was responsible for the interpretation of the data, and the critical review of the manuscript. EV was responsible for the conceptualisation of the idea of the study, interpretation of the data and preparation of the manuscript. All authors read and approved the final manuscript.

Funding The authors have not declared a specific grant for this research from any funding agency in the public, commercial or not-for-profit sectors.

Competing interests EV is an Editorial Board Member of BMJ Open Sport \& Exercise Medicine.

Patient and public involvement Patients and/or the public were not involved in the design, or conduct, or reporting, or dissemination plans of this research.

\section{Patient consent for publication Not applicable.}

Ethics approval To provide insight into the number of novice athletes and their injury risk compared to their experienced counterparts, data were collected from a large population-based retrospective cross-sectional study, 'Injuries and Physical Activity in the Netherlands' (IPAN). IPAN is an existing database, data were registered anonymously, and respondents cannot be traced with this data. Consequently, no Ethics Committee approval was acquired.

Provenance and peer review Not commissioned; externally peer reviewed. Data availability statement Data are available upon reasonable request.

Open access This is an open access article distributed in accordance with the Creative Commons Attribution Non Commercial (CC BY-NC 4.0) license, which permits others to distribute, remix, adapt, build upon this work non-commercially, and license their derivative works on different terms, provided the original work is properly cited, appropriate credit is given, any changes made indicated, and the use is non-commercial. See: http://creativecommons.org/licenses/by-nc/4.0/.

\section{ORCID iDs}

Ellen Kemler http://orcid.org/0000-0002-3549-7091

Evert Verhagen http://orcid.org/0000-0001-9227-8234

\section{REFERENCES}

1 DiPietro L, Al-Ansari SS, Biddle SJH, et al. Advancing the global physical activity agenda: recommendations for future research by the 2020 who physical activity and sedentary behavior guidelines development group. Int J Behav Nutr Phys Act 2020;17:143.
2 Ding D, Lawson KD, Kolbe-Alexander TL, et al. The economic burden of physical inactivity: a global analysis of major noncommunicable diseases. Lancet 2016;388:1311-24.

3 Kisser R. The Burden of Sport Injuries in the European Union. Research report D2h of the project "Safety in Sports". Vienna: EuroSafe, 2012.

4 EuroSafe. Injuries in the European Union, summary on injury statistics 2012-2014. Vienna, 2016.

5 Polinder S, Haagsma J, Panneman M, et al. The economic burden of injury: health care and productivity costs of injuries in the Netherlands. Accid Anal Prev 2016;93:92-100.

6 Verhagen E, Bolling C, Finch CF. Caution this drug may cause serious harm! why we must report adverse effects of physical activity promotion. Br J Sports Med 2015;49:1-2.

7 Tonoli C, Cumps E, Aerts I. Incidence, risk factors and prevention of running related injuries in long-distance running: a systematic review. Sport Geneeskunde 2010;43:12-18.

8 Bloemers F, Collard D, Paw MCA, et al. Physical inactivity is a risk factor for physical activity-related injuries in children. $\mathrm{Br} J$ Sports Med 2012;46:669-74.

9 van Beijsterveldt AMCA-M, Stubbe JH, Schmikli SL, et al. Differences in injury risk and characteristics between Dutch amateur and professional soccer players. J Sci Med Sport 2015;18:145-9.

10 Statistics Netherands, downloaded from the website, 2021. Available: www.cbs.nl

11 Sharot T. Weighting survey results. Journal of the Market Research Society 1986;28:269-84.

12 Schmikli SL, Backx FJG, Kemler HJ, et al. National survey on sports injuries in the Netherlands: target populations for sports injury prevention programs. Clin J Sport Med 2009;19:101-6.

13 Pulles I, van den Dool R. Starten en stoppen Met Een sportactiviteit: de zoektocht naar de ideale sportactiviteit, factsheet 2020/29. Mulier Intitiit, Utrecht, 2020.

14 Fokkema T, Hartgens F, Kluitenberg B, et al. Reasons and predictors of discontinuation of running after a running program for novice runners. J Sci Med Sport 2019;22:106-11.

15 Fokkema T, Burggraaff R, Hartgens F, et al. Prognosis and prognostic factors of running-related injuries in novice runners: a prospective cohort study. J Sci Med Sport 2019;22:259-63.

16 Kemler E, Blokland D, Backx F, et al. Differences in injury risk and characteristics of injuries between novice and experienced runners over a 4-year period. Phys Sportsmed 2018;46:485-91.

17 Bahr R, Krosshaug T. Understanding injury mechanisms: a key component of preventing injuries in sport. Br J Sports Med 2005;39:324-9.

18 Bittencourt NFN, Meeuwisse WH, Mendonça LD, et al. Complex systems approach for sports injuries: moving from risk factor identification to injury pattern recognition-narrative review and new concept. Br J Sports Med 2016;50:1309-14.

19 Klügl M, Shrier I, McBain K, et al. The prevention of sport injury: an analysis of 12000 published manuscripts. Clinical Journal of Sport Medicine 2010;20:407-12.

20 Gouttebarge V, Barboza SD, Zwerver J, et al. Preventing injuries among recreational adult volleyball players: results of a prospective randomised controlled trial. J Sports Sci 2020;38:612-8.

21 Barboza SD, Nauta J, Emery C, et al. A warm-up program to reduce injuries in youth field hockey players: a Quasi-Experiment. J Athl Train 2019;54:374-83.

22 Flower J. In the mush. Physician Exec 1999;25:64-6.

23 Verhagen E, Warsen M, Silveira Bolling C. 'I JUST WANT TO RUN': how recreational runners perceive and deal with injuries. BMJ Open Sport Exerc Med 2021;7:e001117.

24 Smits D-W, Backx F, Van Der Worp H, et al. Validity of injury selfreports by novice runners: comparison with reports by sports medicine physicians. Res Sports Med $2019 ; ; 27: 72-87$.

25 Valuri G, Stevenson M, Finch C, et al. The validity of a four week self-recall of sports injuries. Inj Prev 2005;11:135-7.

26 Gabbe BJ, Finch CF, Bennell KL, et al. How valid is a self reported 12 month sports injury history? Br J Sports Med 2003;37:545-7.

27 Harel Y, Overpeck MD, Jones DH, et al. The effects of recall on estimating annual nonfatal injury rates for children and adolescents. Am J Public Health 1994;84:599-605. 